\title{
DECOMISO NO DIREITO ESPANHOL. UMA POSSIBILIDADE PARA O BRASIL, ANTE AS INOVAÇÕES DA LEI N. 13.964, DE 2019?
}

\author{
Flavia do Espirito Santo Batista \\ Advocacia-Geral da União - DF
}

Mauricio Macagnan da Silva

Advocacia-Geral da União - DF

\section{RESUMO}

O presente trabalho buscou analisar a viabilidade político-criminal, sob o aspecto da legitimidade do instituto do Decomiso, a teor das últimas reformas promovidas pela Lei Orgânica da Espanha 1/2015, de 30 de março, ao direito brasileiro.

Palavras-chave: confisco; bens ilícitos; organizações criminosas; garantias constitucionais.

\section{CONSIDERAÇÕES INICIAIS. EVOLUÇÃo HiSTÓRICA DO DIREITO PENAL. DO PACTO SOCIAL AO ESTADO.}

A definição de Estado, em breves e ousadas linhas, pode ser descrita como uma sociedade, fixada em um território, a qual exerce, dentro desses limites, o poder político, cujo objetivo é a busca do bem comum.

Bobbio (2000, p. 134) continuaria afirmando que o Estado, do ponto de vista jurídico, é, da mesma forma, o sistema jurídico ao qual se atribui a aplicação de suas regras, a fim de garantir o monopólio da força e o exercício exclusivo do poder coercitivo. Nesta senda, o Estado representaria a manifestação da vontade dos indivíduos (pacto social) ${ }^{1}$ e, simplesmente, desempenhando papel negativo na garantia das liberdades individuais.

1 Thomas Hobbes, John Locke e Jean Jacques Rousseau, autores contratualistas, que viveram entre os séculos XVI e XVIII, estudiosos sobre o pacto social, que teoriza a mudança do estado da natureza, para o estabelecimento de regras de interação social e as instituições de poder político que foram estabelecidas do Estado. 
De fato, a evolução histórica deste conceito de autoridade social converge com a construção da ideia de Estado que, desempenhando funções políticas, sociais, econômicas e jurídicas, é responsável por promover o bem comum, bem como promover a ordem pública e a paz social. Ainda nesta seara, o surgimento do direito penal se confunde com o surgimento da própria sociedade.

Após o período primitivo, de caráter essencialmente religioso, havia uma preocupação em tornar o sistema repressivo secular, punindo-se o perverso infrator e, para tanto, os aspectos individuais e públicos do delito foram levados em consideração para a aplicação da reprimenda correlata. Os crimes, portanto, passaram a ser divididos em crimes públicos (crimina pública) e privados (delicta privata).

\section{Direito PENAL COMO IUS PUNIENDI PERTENCENTE EXCLUSIVAMENTE AO ESTADO}

O direito penal, como ciência jurídica, possui o escopo de proteger os valores fundamentais para a subsistência do corpus social, ou seja, os chamados bens jurídicos, pertencendo privativamente ao Estado o monopólio do direito público subjetivo de punir como expressão clássica de sua soberania.

Desta feita, o ius puniendi pode, portanto, ser definido como a prerrogativa do ente estatal no desempenho de seu papel como garantidor da ordem pública e do equilíbrio social.

Para Kelsen (1999), do ponto de vista psicológico, a função de qualquer ordem social é incentivar determinados comportamentos humanos que estão subordinados à ordem jurídica punitiva editada por Leis. Espera-se, assim, que os indivíduos não realizem determinadas ações consideradas socialmente prejudiciais e, ao contrário, passem a executar ações outras consideradas socialmente úteis ${ }^{2}$. Essa função motivadora é exercida pelo arcabouço de regras que prescrevem ou proíbem as ações humanas.

2 KELSEN, Hans. Teoria pura do direito. Tradução de João Baptista Machado. 8. ed. São Paulo: WMF Martins Fontes, 1999, p. 17. 
Seguindo-se a premissa do autor citado, de acordo com a forma como as ações humanas são prescritas ou proibidas, diferentes tipos podem ser distinguidos, de modo que a ordem social pode, ainda, prescrever uma determinada conduta humana sem vinculá-la à sua observância ou ao seu descumprimento, sem qualquer consequência.

Noutro lado, determinada conduta humana também pode ser instigada pela legislação vigente e, ao mesmo tempo, pode resultar na concessão de uma vantagem, ao passo que a conduta oposta pode ser vinculada a uma sanção (no sentido mais amplo da palavra). Está-se diante do princípio retributivo (Vergeltung) 3 , na medida em que recompensa e o castigo podem ser compreendidos no conceito de sanção.

No entanto, em geral, é chamada por sanção apenas a pena que se traduz na privação dos bens caros aos indivíduos, tais como vida, saúde, liberdade, honra, valores econômicos - para a aplicação como consequência de uma conduta reprovável; não mais sob o binômio prêmio-recompensa, mas como uma sanção - a pena - em seu sentido hermenêutico mais amplo, a qual deve ser aplicada contra a vontade dos afetados e, em caso de resistência, através do uso da força física.

\section{A humanizaÇão do direito PENAL}

Inegavelmente, os séculos XVII e XVIII foram marcados pela crescente importância da burguesia, classe social que defendia o desenvolvimento do capitalismo como modelo econômico. Nesse contexto, houve grandes conflitos de interesse entre a nobreza e os burgueses, os quais figuravam como estratos sociais emergentes.

Certamente, o liberalismo burguês tinha seu esteio em um sistema de ideias que ganhou corpo através do movimento cultural conhecido como Iluminismo ou Filosofia das Luzes. Por certo, foi no período do Iluminismo que começou o chamado período humanitário do direito penal, movimento este que levou à reforma das leis e à administração da justiça criminal no final do século XVIII.

3 Substantivo alemão feminino, que pode ser traduzido como retaliação. Impende notar que a expressão - retribuição como princípio legal - (retaliação como princípio) está associada com a assertiva contida no Lex Talionis (lex como lei, tálio, talis, tal, idêntico). 
Importa esclarecer (sem o aprofundamento merecido), que o Iluminismo emergiu na França no século XVII. No entanto, o auge desse movimento ocorreu na primeira metade do século XVIII. Seus pensadores defenderam a predominância da razão sobre a visão teocêntrica (religiosa), que dominava a Europa desde a Idade Média. De acordo com os filósofos do Iluminismo, esta nova forma de pensar tinha a intenção de iluminar a "escuridão" na qual a sociedade estava centrada.

O Iluminismo foi marcado por pensadores como Montesquieu, Voltaire, Rousseau, D’Alembert, Locke, fundamentais para a construção de tal período e para a transformação liberal e humanista do direito.

Em síntese, os pensadores iluministas se basearam numa nova ideologia que teria repercussões na aplicação da justiça sem arbitrariedade, sendo que o pensamento predominante era contra qualquer crueldade.

Sobre as penas e sua utilidade, Montesquieu (2016, p. 185) alertou que:

La experiencia ha hecho notar que en los países donde las penas son ligeras, impresionan a los ciudadanos tanto como en otros países las más duras. Cuando surge en un Estado una inconveniencia grave o imprevista, un gobierno violento quiere corregirla de una manera súbita; y en lugar de hacer ejecutar las leyes vigentes, establece una pena cruel que enseguida corta el mal. Pero se gasta el resorte: la imaginación se acostumbra a la pena extraordinaria y grande, como antes se había hecho a la menor; y perdido el miedo a ésta, no hay más remedio que mantener la otra.

Em mesma linha de intelecção, nada mais atual do que as palavras de Michel Foucault (1987, p. 19) ${ }^{4}$ sobre o assunto em discussão, ao elucidar que o poder sobre o corpo tampouco deixou de existir totalmente até meados do século XIX. Sem dúvida, a pena não mais se centralizava no suplício como técnica de sofrimento, mas no tomar como objeto a perda de um bem ou de um direito.

4 FOUCAULT, Michel. Vigiar e punir: nascimento da prisão; tradução de Raquel Ramalhete. Petrópolis, Vozes, 1987, p. 19. 
Contudo, continua o autor, castigos como trabalhos forçados ou prisão - privação pura e simples da liberdade - nunca funcionaram sem certos complementos punitivos referentes ao corpo: redução alimentar, privação sexual, expiação física, masmorra. Consequências não intencionais, mas inevitáveis da própria prisão? $\mathrm{Na}$ realidade, a prisão, nos seus dispositivos mais explícitos, sempre aplicou certas medidas de sofrimento físico. A crítica ao sistema penitenciário, na primeira metade do século XIX (a prisão não é bastante punitiva: em suma, os detentos têm menos fome, menos frio e privações que muitos pobres ou operários), indica um postulado que jamais foi efetivamente levantado: é justo que o condenado sofra mais que os outros homens?

Beccaria (1993, p. 216), em mesmo aspecto, também ensinou sobre a inutilidade da pena de morte e do paradoxo entre dotar o Estado Soberano deste poder, que lhe foi outorgado por seus próprios indivíduos, uma vez que a soberania se origina, conceitualmente, da renúncia do poder pelo povo, que o transfere para o Estado (Soberano) ${ }^{6}$.

Seguindo-se, arremata o autor, ao elucidar que a pena de morte não é um direito (do Estado), mas apenas uma guerra de uma nação contra seu cidadão, porque considera útil ou necessária à sua destruição. ${ }^{7}$

Partindo-se das premissas lançadas, teve início a estruturação do direito penal como ciência inserida no estudo do direito, ao tempo que a aplicação da execução penal passou a ter uma preocupação enraizada nesses pontos de relevância que, dadas as mudanças estruturais vivenciadas pelas sociedades no pós-guerra, persistem até os dias atuais.

5 Ibidem, idem.

6 Ibidem, p. 216. Texto original: Esta inútil prodigalidad de suplicios, que nunca ha conseguido hacer mejores los hombres, me ha obligado a examinar si es la muerte verdaderamente-útil y justa en un Gobierno bien organizado. ¿Qué derecho pueden atribuirse estos para despedazar a sus semejantes? Por cierto no el que resulta la Soberanía y de las Leyes. Estas, más que una suma de porciones de libertad de cada uno, que representan la voluntad general, como agregado de las particulares? ¿Quién es aquel que ha querido dejar a los otros hombres el arbitrio de hacerlo morir?

7 Ibidem, p. 17. Texto original: No es, pues, la pena de muerte derecho, cuando tengo demostrado que no puede serlo: es solo una guerra de la Nación contra un Ciudadano, porque juzga útil o necesaria la destrucción de su ser. 


\section{O Direito PENAL NA PERSPECTIVA ATUAL}

\subsection{DA VEDAÇÃo Às PENAS DE TORTURA}

Com o estudo do comportamento humano, e também com a ajuda da psicologia, da psiquiatria, bem como da ética, dentre outras ciências filosóficas, chegou-se à conclusão de que o direito penal não pode ser visto apenas como mecanismo de repreensão desmesurada, mas deve ser entendido como método positivo-construtivo de ressocialização.

A preocupação com a reinserção na sociedade do individuo-autor do crime, bem como as razões que o levaram à prática do delito, devem fazem parte do estudo da criminologia, na qual a preocupação com a situação econômica, social e cultural do infrator é deveras importante para a aplicação do direito penal.

É de relevo notar que o direito penal estabelecido nos estados alemães (landes) decorre do direito penal aplicado nos países modernos, onde a figura do infrator não é a de um rival da sociedade, mas de alguém que, ao não se adaptar às regras cogentes, sofrerá uma sanção proporcional à ação comissiva ou omissiva praticada.

No entanto, ainda noticiamos a aplicação de penalidades que são díspares e ineficazes, como, por exemplo, penas corporais que traduzem extrema violência, como cortar as mãos e braços, em casos de furto ou roubo.

Essas penalidades são heranças de pensamentos antigos, mas permanecem válidas em certas partes do mundo. Em países com relações severas com criminosos, é constantemente perceptível que sentenças de natureza perpétua ou de morte estão sempre sendo aplicadas (e justificadas).

Para Vieira (2007), aliás, o direito penal, atualmente, é observado sob a ótica dos movimentos modernos que debatem sobre sua aplicabilidade, destacando os aspectos mais relevantes que levaram a justiça criminal ao nível atual do intelecto, permeada por princípios, de acordo com a evolução da vida social. 
Não se pode olvidar que a Declaração Universal dos Direitos Humanos de1948 marcou o reconhecimento, ao menos formal, da proibição da tortura, ao preceituar em seu art. $5^{\circ}$ que "ninguém deverá ser submetido a tortura nem a penas ou tratamentos cruéis, desumanos ou degradantes".

Em seu citado art. $5^{\circ}$, textualmente afirmou-se que ninguém será submetido a tortura nem a penas ou tratamentos cruéis, desumanos ou degradantes. Entretanto, não se definiu, do ponto de vista jurídico, o que constitui tortura, tampouco fora definido o conceito de tratamentos ou penas cruéis.

A assertiva restou acolhida pelos sistemas regionais de proteção de direitos humanos, que historicamente se sucederam à criação da ONU, enquanto sistema mundial de proteção dos direitos humanos ${ }^{8}$.

Em 1950, por força do Tratado de Roma, foi criado o Sistema Europeu de Proteção dos Direitos Humanos, como uma carta de direitos que norteia e codifica uma gama de direitos e garantias individuais. Posteriormente, em 1988, na América Latina, a Constituição da República Federativa do Brasil também trouxe em seu artigo $5^{\circ 9}$ a vedação à tortura e à tratamento desumano ou degradante ${ }^{10}$ :

Um bom exemplo a ser citado, tendo em vista o tema aqui em cotejo, é a própria Constituição da Espanha de $1978^{11}$, a qual aboliu a pena de morte e não permite a tortura ou tratamento desumano ou degradante.

8 Idem. Ibidem.

9 Art. $5^{\circ}$ Todos são iguais perante a lei, sem distinção de qualquer natureza, garantindo-se aos brasileiros e aos estrangeiros residentes no País a inviolabilidade do direito à vida, à liberdade, à igualdade, à segurança e à propriedade, nos termos seguintes:

III - ninguém será submetido a tortura nem a tratamento desumano ou degradante;

10 Devemos registar que a escravidão no Brasil contribuiu em muito para a cultura da degradação física como modus operandi de punição. No Poema Navio Negreiro, de Castro Alves (1847 - 1871), fazse nítida esta marca histórica, em que negros escravizados, trazidos ao Novo Mundo pelos navios negreiros, eram submetidos a deploráveis práticas de tortura. "Ontem plena liberdade, a vontade por poder... Hoje... cúmulo de maldade, nem são livres p'ra morrer.. Prende-os a mesma corrente - Férrea, lúgubre serpente - Nas roscas da escravidão. Eassim zombando da morte, dança a lúgubre corte ao som do açoute... Irrisão!"

11 Artigo 15: Todos têm direito à vida e à integridade física e moral, sem que, em qualquer caso, seja submetido a tortura ou a tratamento ou punição desumano ou degradante. A pena de morte é abolida, exceto como pode ser previsto nas leis penais militares para os tempos de guerra (tradução dos autores). 
Nesta seara de construção dos alicerces do Estado de Direito, cujo fundamento e finalidade são a tutela das liberdades do cidadão face às diversas formas de exercício (arbitrário) de poder, nasce a teoria geral do garantismo, tendo como premissa a máxima respeitabilidade aos direitos fundamentais e às garantias processuais, para que seja coibida qualquer arbitrariedade eventualmente praticada no desempenhar da persecução penal pelo Estado.

Sobre o tema, Ferrajoli (2016, p. 785-786) defendeu a necessidade de observância de princípios básicos - que ele chamou de axiomas - para que um determinado sistema normativo-penal pudesse ser considerado válido ${ }^{12}$. Referia-se aos dez axiomas cuja função precípua é a de legitimar o poder punitivo estatal.

Tem-se, pois, que os três significados básicos de um modelo penal garantista pode ser sintetizado em parâmetros de racionalidade, justiça e legitimidade; e intervenção punitiva.

Em mesma senda, em um Estado (Constitucional) Democrático, veda-se a criação, aplicação e execução de qualquer medida que viole a dignidade humana. Tal premissa apresenta-se como uma garantia à ordem material e restritiva ao direito penal, que resguarda, inclusive, o alcance de sua própria finalidade.

Neste mote, não se pode olvidar que, apesar das garantias às atuações arbitrárias, que, frise-se, são de importância ímpar, as reprimendas ao cometimento de condutas delitivas urgem ser efetivas, para que, de verdade, o crime não compense.

Assim, ao longo das últimas décadas, o constrangimento patrimonial veio a ganhar relevância como medida penal constritiva, vindo a ser minoradas, gradativamente, as penas restritivas de liberdade ${ }^{13}$.

12 (1) Nulla poena sine crimine; (2) Nullum crimen sine lege; 3) Nulla lex poenalis sine necessitate; (4) Nulla necessitas sine injuria; 5) Nulla injuria sine actione; (6) Nulla actio sine culpa; (7) Nulla culpa sine judici; (8) Nulla judicium sine accustone; (9) Nulla accusatio sine probatione; 10) Nulla probatio sine defensione.

13 Aqui convém ressaltar um contraponto, no que toca à elitização das penas, de modo que o cárcere ainda serve apenas à população pertencente aos estratos sociais menos favorecidos, devendo-se ter em mente que o comportamento desviante é apreendido e reproduzido, não herdado. 


\subsection{Da RelativizaçÃo das PENAS CORPORAIS. DA CONS- TRIÇÃO PATRIMONIAL E DO PERDIMENTO DE BENS À LUZ DO DIREITO PENAL BRASILEIRO}

Não se pode ignorar o papel do direito penal como um dos instrumentos mais efetivos de proteção aos direitos fundamentais. Entretanto, com a evolução das organizações criminosas, que perpassa pelas complexidades delitivas, a pena de perdimento de bens passou a ser vista como solução eficaz para coibir tais condutas.

Se quando da institucionalização do liberalismo o Estado era o repressor social mais incisivo, atualmente, o Estado necessitou desenvolver um papel proativo de relevo, em defesa dos direitos da sociedade, já que as organizações criminosas passaram a operar de forma simbiótica e metamórfica ${ }^{14}$, exigindo dos poderes públicos a mesma capacidade de adaptação.

Decerto, a Constituição Federal de $1988^{15}$ já consagrava a possibilidade do perdimento de bens como desdobramento da condenação penal.

Em densificação ao texto constitucional, a norma geral que disciplina o perdimento de bens está contida no Código Penal Brasileiro, Decreto-Lei n. 2.848, de 7 de dezembro, de 1940, com alterações promovidas pela Lei n. 7.209, de 1984, especificamente em seu art. $91^{16}$, que trata dos efeitos da condenação criminal, funcionando como acessória à pena principal.

14 Sobre o tema, Eleições e milícias no Rio de Janeiro: simbiose entre o poder público e o crime organizado. Mendonça, Thaiane. Disponível em : https://gedes-unesp.org/eleicoes-e-milicias-norio-de-janeiro-simbiose-entre-o-poder-publico-e-o-crime-organizado/. Acesso em: 31 maio 2021.

15 Art. $5^{\circ}, \mathrm{XLV}$ - nenhuma pena passará da pessoa do condenado, podendo a obrigação de reparar o dano e a decretação do perdimento de bens ser, nos termos da lei, estendidas aos sucessores e contra eles executadas, até o limite do valor do patrimônio transferido; XLVI - a lei regulará a individualização da pena e adotará, entre outras, as seguintes: a) privação ou restrição da liberdade; b) perda de bens; c) multa; d) prestação social alternativa; e) suspensão ou interdição de direitos;

16 Art. 91. São efeitos da condenação: I - tornar certa a obrigação de indenizar o dano causado pelo crime; II - a perda em favor da União, ressalvado o direito do lesado ou de terceiro de boa-fé: a) dos instrumentos do crime, desde que consistam em coisas cujo fabrico, alienação, uso, porte ou detenção constitua fato ilícito; b) do produto do crime ou de qualquer bem ou valor que constitua proveito auferido pelo agente com a prática do fato criminosos. 
Noutro norte, a Lei n. 9.714, de 1998, veio a estabelecer o sistema de penas alternativas ou substitutivas às penas privativas de liberdade, tendo como principal objetivo a restituição do prejuízo causado pelo infrator, de modo a adequar a efetiva sanção para os crimes contra o sistema financeiro, e principalmente, contra o branqueamento/lavagem de capitais. Segue-se a transcrição:

Art. 44. As penas restritivas de direitos são autônomas e substituem as privativas de liberdade, quando: (Redação dada pela Lei n. 9.714, de 1998)

I - aplicada pena privativa de liberdade não superior a quatro anos e o crime não for cometido com violência ou grave ameaça à pessoa ou, qualquer que seja a pena aplicada, se o crime for culposo;(Redação dada pela Lei n. 9.714, de 1998)

II - o réu não for reincidente em crime doloso; (Redação dada pela Lei n. 9.714, de 1998)

III - a culpabilidade, os antecedentes, a conduta social e a personalidade do condenado, bem como os motivos e as circunstâncias indicarem que essa substituição seja suficiente. (BRASIL, 1998)

Tais preceitos regulamentam a possibilidade de se imputar a penalidade de perda de bens e valores, ainda que lícitos, pertencentes aos réus, no limite do prejuízo causado pela prática da conduta delitiva. Para tanto, o perdimento é aplicado como pena principal, em substituição à pena privativa de liberdade, de modo que a aplicabilidade do art. 44 do Código Penal não se confunde com a pena acessória prevista no art. 91 do mesmo diploma legal.

Contudo, levando-se em consideração os crimes praticados por organização criminosa, na maioria das vezes, era vedada a substituição de pena corporal por restritivas de direito, fato que dificultava a aplicação plena da norma em comento.

Nesta perspectiva, foi gestada a Lei n. 12.694, de 2012, a qual previu no parágrafo $1^{\circ}$ do artigo $91^{17}$ do Código Penal a ampliação das hipóteses do denominado confisco por equivalência.

17 Art. 91 caput (...). $\$ 1$ o Poderá ser decretada a perda de bens ou valores equivalentes ao produto ou proveito do crime quando estes não forem encontrados ou quando se localizarem no exterior. (Incluído pela Lei n. 12.694, de 2012).\$2o Na hipótese do $₫ 10$, as medidas assecuratórias previstas na legislação processual poderão abranger bens ou valores equivalentes do investigado ou acusado para posterior decretação de perda.(Incluído pela Lei n. 12.694, de 2012) 
Decerto, esta nova roupagem do perdimento de bens não é novidade no cenário internacional, encontrando-se, inclusive, em tratados internacionais dos quais o Brasil é signatário.

Os principais eixos são a Convenção das Nações Unidas contra o Tráfico Ilícito de Estupefacientes e de Substâncias Psicotrópicas, a Convenção das Nações Unidas contra a Criminalidade Organizada Transnacional (Convenção de Palermo) e a Convenção das Nações Unidas contra a Corrupção (Convenção de Mérida).

Assim, visando ainda maior efetividade à máxima the crimes doesn't pay ${ }^{18}$, por força da Lei n. 13.964, de 2019, foi inserido no CP pátrio o artigo 91-A como efeito da condenação para infraçóes com pena máxima acima de 6 anos de reclusão, sendo franqueado ao réu comprovar a licitude de seu patrimônio. Para tornar mais fácil o cotejo da norma, verbis:

Art. 91-A. Na hipótese de condenação por infrações às quais a lei comine pena máxima superior a 6 (seis) anos de reclusão, poderá ser decretada a perda, como produto ou proveito do crime, dos bens correspondentes à diferença entre o valor do patrimônio do condenado e aquele que seja compatível com o seu rendimento lícito. (Incluído pela Lei n. 13.964, de 2019)

$\$ 1^{\circ}$ Para efeito da perda prevista no caput deste artigo, entende-se por patrimônio do condenado todos os bens: (Incluído pela Lei n. 13.964, de 2019)

I - de sua titularidade, ou em relação aos quais ele tenha o domínio e o benefício direto ou indireto, na data da infração penal ou recebidos posteriormente; e... (Incluído pela Lei n. 13.964, de 2019)

II - transferidos a terceiros a título gratuito ou mediante contraprestação irrisória, a partir do início da atividade criminal. (Incluído pela Lei n. 13.964, de 2019)

$\$ 2^{\circ} \mathrm{O}$ condenado poderá demonstrar a inexistência da incompatibilidade ou a procedência lícita do patrimônio. (Incluído pela Lei n. 13.964, de 2019)

18 Para pesquisa sobre tema, Oficina de las Naciones Unidas contra la Droga y el Delito - UNODC, Disponível em: https://www.unodc.org/unodc/en/corruption/uncac.html. Acesso em: 28 maio 2021. 
$\$ 3^{\circ}$ A perda prevista neste artigo deverá ser requerida expressamente pelo Ministério Público, por ocasião do oferecimento da denúncia, com indicação da diferença apurada. (Incluído pela Lei n. 13.964, de 2019)

$\$ 4^{\circ} \mathrm{Na}$ sentença condenatória, o juiz deve declarar o valor da diferença apurada e especificar os bens cuja perda for decretada. (Incluído pela Lei n. 13.964, de 2019)

$\$ 5^{\circ}$ Os instrumentos utilizados para a prática de crimes por organizações criminosas e milícias deverão ser declarados perdidos em favor da União ou do Estado, dependendo da Justiça onde tramita a ação penal, ainda que não ponham em perigo a segurança das pessoas, a moral ou a ordem pública, nem ofereçam sério risco de ser utilizados para o cometimento de novos crimes. (BRASIL, 2019)

$\mathrm{O}$ preceito em análise busca a atender às recomendações internacionais com o escopo de coibir o crime organizado, ao alinhar a legislação brasileira em coordenação com os sistemas jurídicos internacionais que já adotavam tais medidas constritivas.

Repisando-se o tema em debate, o confisco ampliado tem como fundamento o $\$ 8^{\circ}$ do art. 31 da Convenção de Mérida, o qual estabelece que os Estados Partes poderão considerar a possibilidade de exigir a demonstração da origem lícita do alegado produto de delito ou de outros bens expostos ao confisco, nos limites da legislação interna bem como nos moldes correlatos ao sistema processual de cada estado-parte.

No Brasil, a inovação legislativa em comento fora desafiada pela propositura da Ação Direta de Inconstitucionalidade n. 6304, pela Associação Brasileira dos Advogados Criminalistas (Abracrim) ${ }^{19}$. A citada ação direta de inconstitucionalidade trata de controvérsia acerca da constitucionalidade da nova disciplina trazida pela Lei n. 13.964, de 2019, e, dentre outros pontos, sobre o perdimento de bens, com o argumento de que se teria criado pena de "confisco", em violação ao princípio da individualização da pena e da função social da propriedade.

Impende ressaltar que o Supremo Tribunal Federal ainda não se manifestou acerca da ação proposta, sendo certo que a Advocacia-Geral da União ${ }^{20}$ se posicionou pela constitucionalidade da medida,

19 Supremo Tribunal Federal. Ação Direita de Inconstitucionalidade n. 6304. Disponível em: http:// portal.stf.jus.br/processos/detalhe.asp?incidente=5843708. Disponível em: 28 maio 2021 .

20 Supremo Tribunal Federal. ADI n. 6.304. Manifestação da Advocacia-Geral da União. Disponível 
pois a norma federal sob análise obedece ao primado da proporcionalidade, sendo a correta resposta estatal ao recrudescimento dos crimes, impedindo o proveito econômico que constitui a principal finalidade da maioria das atividades criminosas.

\section{O DECOMISO NA ESPANHA}

Conforme já asseverado neste trabalho acadêmico, o crescimento dos crimes de lavagem de dinheiro, associados a outros crimes econômicos, também ligados à corrupção administrativa, exigiu do Estado maior desempenho de sua capacidade persecutória. Ora, a característica comum deste conjunto de crimes está na obtenção de vultosos lucros por seus agentes, fato que tem forçado à reorientação dos objetivos da política penal mundial.

Portanto, uma das prioridades no combate à criminalidade centra-se na revitalização do conceito de confisco dos instrumentos e lucros do crime, tornando as investigações focadas na identificação e apreensão de produtos de origem criminosa.

A Diretiva Europeia 2014/42/UE, de 3 de abril, elaborada no âmbito do Parlamento Europeu e de seu Conselho, dispôs sobre a apreensão e confisco de instrumentos e de produtos de delitos, como terrorismo e o tráfico de entorpecentes.

Tal Diretiva orientou aos Estados-membros a adoção as medidas necessárias para a recuperação de ativos provenientes de práticas ilícitas, inclusive quando fora verificado que o valor dos bens é desproporcional ao rendimento legítimo dos réus ${ }^{21}$.

em: $\quad$ https://redir.stf.jus.br/paginadorpub/paginador.jsp?docTP=TP\&docID=753841792\&prc ID=6005276\#. Acesso em: 28 maio 2021.

21 (11) É necessário clarificar a atual definição de produtos do crime de modo a incluir não só o produto direto das atividades criminosas, mas também todos os seus ganhos indiretos, incluindo o reinvestimento ou a transformação posterior de produtos diretos. Assim, o produto pode incluir quaisquer bens, inclusive os que tenham sido transformados ou convertidos, no todo ou em parte, noutros bens, e os que tenham sido misturados com bens adquiridos de fonte legítima, no montante correspondente ao valor estimado do produto do crime que entrou na mistura. Pode igualmente incluir o rendimento ou outros ganhos derivados do produto do crime, ou dos bens em que esse produto tenha sido transformado, convertido ou misturado

(10) Os Estados-Membros são livres de desencadear procedimentos de perda que estejam ligados a um processo penal instaurado perante qualquer tribunal competente.

(14) Para a perda de instrumentos e de produtos do crime na sequência da decisão definitiva de um tribunal, ou de bens de valor equivalente ao desses instrumentos e produtos, deverá ser aplicada 
Como exemplo, a Espanha editou a Lei Orgânica 1/2015, que realizou a reforma da sua legislação penal, com entrada em vigor em $1^{\circ}$ de julho de 2015. Faz-se a transcrição da norma para melhor compreensão do tema:

\section{Artículo $127^{22}$.}

1. Toda pena que se imponga por un delito doloso llevará consigo la pérdida de los efectos que de él provengan y de los bienes, medios o instrumentos con que se haya preparado o ejecutado, así como de las ganancias provenientes del delito, cualesquiera que sean las transformaciones que hubieren podido experimentar.

2. En los casos en que la ley prevea la imposición de una pena privativa de libertad superior a un año por la comisión de un delito imprudente, el juez o tribunal podrá acordar la pérdida de los efectos que provengan del mismo y de los bienes, medios o instrumentos con que se haya preparado o ejecutado, así como de las ganancias provenientes del delito, cualesquiera que sean las transformaciones que hubieran podido experimentar.

3. Si por cualquier circunstancia no fuera posible el decomiso de los bienes señalados en los apartados anteriores de este artículo, se acordará el decomiso de otros bienes por una cantidad que corresponda al valor económico de los mismos, y al de las ganancias que se hubieran obtenido de ellos. De igual modo se procederá cuando se acuerde el decomiso de bienes, efectos o ganancias determinados, pero su valor sea inferior al que tenían en el momento de su adquisición. (ESPANHA, 1995)

\footnotetext{
a definição alargada de infraçôes penais abrangidas pela presente diretiva. A Decisão-Quadro 2001/500/JAI exige que os Estados-Membros possibilitem a perda de instrumentos e de produtos do crime na sequência de uma condenação definitiva, bem como a perda de bens cujo valor corresponda ao desses instrumentos e produtos. Essas obrigações deverão manter-se no que toca às infrações penais não abrangidas pela presente diretiva, e a definição de produtos dela constante deverá ser interpretada do mesmo modo no que respeita às infrações penais não abrangidas pela presente diretiva. Os EstadosMembros são livres de definir a perda de bens de valor equivalente como medida subsidiária ou alternativa à perda direta, consoante adequado nos termos do direito nacional. Diretiva 2014/42/ UE do Parlamento Europeu e do Conselho de 3 de abril de 2014 sobre o congelamento e a perda dos instrumentos e produtos do crime na União Europeia. Disponível em: https://eur-lex.europa.eu/ legal-content/PT/TXT/PDF/?uri=CELEX:32014L0042\&from=EN. Acesso em: 30 maio 2021.

22 Código Penal Espanhol. Disponível em: https://www.boe.es/buscar/act. php?id=BOE-A-1995-25444. Acesso em: 01 jun. 2021.
} 


\subsection{DeComiso Ampliado}

$\mathrm{Na}$ Espanha, o decomiso ampliado está previsto no art. 127 bis del Código Penal ${ }^{23}$. Em breve contextualização, caracteriza-se pelo fato de que os bens ou lucros confiscados podem proceder de outras atividades ilícitas do condenado, distintas, inclusive, das condutas perquiridas no bojo da ação penal perpetrada.

Art. 127 bis - Decomiso ampliado

El juez o tribunal ordenará también el decomiso de los bienes, efectos y ganancias pertenecientes a una persona condenada por alguno de los siguientes delitos cuando resuelva, a partir de indicios objetivos fundados, que los bienes o efectos provienen de una actividad delictiva, y no se acredite su origen lícito:

Por essa razão, o decomiso alargado não se baseia na comprovação da conexão causal entre a atividade criminosa e o enriquecimento do acusado, mas na constatação pelo juiz, com base em indícios bem fundamentados e objetivos, de que outras atividades criminosas distintas daquelas para as quais o réu restou condenado foram praticadas.

O decomiso, desse modo, não se insere como sanção penal, porém como medida pela qual a evolução patrimonial ilícita subjacente à atividade criminosa é esvaziada.

A partir da citada reforma, o artigo 127 ter $^{24}$ _do Código Penal

23 Ley Orgánica 10/1995, de 23 de noviembre de 1995. Disponivel em: BOE.es - BOE-A-1995-25444 Ley Orgánica 10/1995, de 23 de noviembre, del Código Penal.BOE.es.

24 Artículo 127 ter.

1. El juez o tribunal podrá acordar el decomiso previsto en los artículos anteriores aunque no medie sentencia de condena, cuando la situación patrimonial ilícita quede acreditada en un proceso contradictorio y se trate de alguno de los siguientes supuestos:

a) Que el sujeto haya fallecido o sufra una enfermedad crónica que impida su enjuiciamiento y exista el riesgo de que puedan prescribir los hechos,

b) se encuentre en rebeldía y ello impida que los hechos puedan ser enjuiciados dentro de un plazo razonable, $o$

c) no se le imponga pena por estar exento de responsabilidad criminal o por haberse ésta extinguido.

2. El decomiso al que se refiere este artículo solamente podrá dirigirse contra quien haya sido formalmente acusado o contra el imputado con relación al que existan indicios racionales de criminalidad cuando las situaciones a que se refiere el apartado anterior hubieran impedido la continuación del procedimiento penal. 
Espanhol ${ }^{25}$ passou a prever o confisco sem julgamento (condenação) do réu, o que tornou necessário também reformar a lei processual penal, para reafirmar o procedimento contraditório (Lecrim).

Para tanto, foi editada a Lei $41 / 2015$, de 5 de outubro ${ }^{26}$, de modificação da Ley de Enjuiciamiento Criminal (Lei de Processo Penal), para conferir maior agilidade à justiça criminal, ao mesmo tempo em que se buscou fortalecer as garantias processuais, com a criação do Livro IV, com um novo Título III - Da intervenção de terceiros afetados pelo confisco e do procedimento de confisco autônomo ${ }^{27}$.

Nota-se que, a rigor, não se trata de uma sanção penal, mas sim de uma imputação fundada na presunção de que os bens ilícitos são necessariamente produto de atividades criminosas, ainda que segregadas do crime pelo qual o réu foi condenado.

Assim, o decomiso ampliado permitirá que juízes e tribunais, no caso de condenações por crimes que normalmente geram uma fonte permanente de renda, ex vi tráfico de drogas, ordenem o confisco dos bens do condenado por outras atividades criminosas.

Contudo, para que a presunção para a condena não venha a ofender aos primados constitucionais, a própria lei estabeleceu um conjunto de parâmetros interpretativos que se referem aos indícios mais comuns que podem levar à afirmação da origem criminosa dos bens.

25 Ressalta-se que por força da Ley Orgánica 5/2010 a Espanha já havia iniciado a modernização de sua legislação.

26 Ley de Enjuiciamiento Criminal Español. Disponível em: https://www.boe.es/buscar/pdf/2015/ BOE-A-2015-10726-consolidado.pdf. Acesso em: 01 jun. 2021.

27 Artículo 127 quater.

1. Los jueces y tribunales podrán acordar también el decomiso de los bienes, efectos y ganancias a que se refieren los artículos anteriores que hayan sido transferidos a terceras personas, o de un valor equivalente a los mismos, en los siguientes casos:

a) En el caso de los efectos y ganancias, cuando los hubieran adquirido con conocimiento de que proceden de una actividad ilícita o cuando una persona diligente habría tenido motivos para sospechar, en las circunstancias del caso, de su origen ilícito.

b) En el caso de otros bienes, cuando los hubieran adquirido con conocimiento de que de este modo se dificultaba su decomiso o cuando una persona diligente habría tenido motivos para sospechar, en la circunstancias del caso, que de ese modo se dificultaba su decomiso.

2. Se presumirá, salvo prueba en contrario, que el tercero ha conocido o ha tenido motivos para sospechar que se trataba de bienes procedentes de una actividad ilícita o que eran transferidos para evitar su decomiso, cuando los bienes o efectos le hubieran sido transferidos a título gratuito o por un precio inferior al real de mercado. 
Tais evidências podem ser vistas quando (a) a desproporção entre o valor do imóvel e a renda legal da pessoa condenada; (b) a ocultação de propriedade ou de qualquer alienação sobre o imóvel através da utilização de pessoas físicas ou jurídicas interpostas, paraísos fiscais ou territórios sem tributação que escondam ou dificultem a determinação da verdadeira propriedade dos bens; e (c) a transferência de bens ou lucros por meio de transações que dificultem ou impeçam sua localização ou destino e que careçam de justificativa legal ou econômica válida (Código Penal Espanhol, art. 127 bis e 127 quiquies).

\subsection{DECOMISO SEM SENTENÇA (SIN CONDENA)}

Outra inovação relevante encontrada na legislação espanhola refere-se ao confisco de bens sem a necessária condenação penal como medida prévia à recuperação dos bens e valores instrumentos ou produtos do embranquecimento de ativos.

Assim, enquanto a perda clássica, em especial no direito pátrio, pressupõe uma condenação transitada em julgado, a perda alargada, do direito espanhol, e, recentemente, no Brasil, por meio da (ainda) tímida Lei n. 13.964, de 2019, pressupõe exatamente o inverso. Melhor dizendo, há uma condenação no processo criminal principal, mas não uma condenação no processo incidente, o qual tem a finalidade apenas de decretar a perda ampla dos bens presumidamente frutos ou não da atividade delitiva.

Por prescindir de condenação, a perda alargada é classificada como non-conviction based confiscation (confisco não baseado em condenação), ao passo que a perda clássica e a perda por equivalente são qualificadas como conviction based confiscation, porque somente permitem o confisco de bens diretamente oriundos da prática de um ilícito penal (ou de bens em valor correspondente, no caso da perda por equivalente $)^{28}$.

Convém, por derradeiro, asseverar que, no direito espanhol, o confisco sem sentença tem lugar quando o autor morreu ou sofre de

28 Sobre o tema, Ministério Público Federal - 2a Câmara de Coordenação e Revisão. Disponivel em: https://criminal.mppr.mp.br/arquivos/File/02_-_Inovacoes_da_Lei_13-964-2019.pdf. Acesso em: 30 maio 2021. 
uma doença crônica que impeça sua acusação e há o risco de que os fatos possam caducar; estar à revelia e tal fato vier a impedir que os atos processuais sejam praticados dentro de um tempo razoável e, ainda, quando ao réu não lhe possa ser imputada pena (por ser inimputável ou por restar extinta).

\subsection{DeComiso POR VALOR EQUIVALENTE}

O decomiso de valor equivalente possibilita o perdimento de outros bens em valor semelhante ao de origem ilícita quando este não pôde ser apreendido.

Todavia, há casos nos quais não é possível traçar, no âmbito processual, o liame entre o crime e os bens do suposto réu/organização criminosa, ainda que indiretamente. Como exemplo, tem-se a dificuldade em identificar e processar o autor do delito, o falecimento do réu, a impossibilidade (jurídica ou material) de produzir provas quanto à autoria do delito, a própria fuga dos demandados, dentre outros motivos que possam dificultar a persecução penal.

Nessa senda, a medida em debate também pode ser classificada como actio in rem, ou seja, uma vez que a ação judicial se volta contra a coisa em si, e não mais contra o criminoso.

Não há dúvidas de que a perda do patrimônio obtido mediante a prática de crimes é questão premente da política criminal mundial. Neste sentido:

La radical transformación, apenas esbozada, que ha padecido el decomiso se debe, como se anticipó, a motivos de política criminal. El legislador, inicialmente en el plano internacional, decidió que el decomiso, junto al delito de blanqueo de capitales.

Debía erigirse en la herramienta esencial para combatir especialmente la delincuencia organizada así como, con carácter general, aquella otra que tiene como razón de ser la búsqueda de beneficios económicos. Existe la convicción de que tan importante o más que la imposición de una pena a los autores de los hechos resulta la privación de las ganancias que reporta un delito. Solo así se combate eficazmen- 
te esas figuras delictivas. Eso explica la autonomía que ha cobrado el decomiso respecto de la pena. Tal es el ímpetu del legislador por el decomiso de bienes en esos supuestos que, en alguna de sus modalidades, se llega a acordar sin que exista prueba de la comisión de un delito, decomiso ampliado, o bien estipulando una presunción legal iuris tantum de la procedencia delictiva del patrimonio, decomiso por reiteración delictiva o hat trick ${ }^{29}$. (DÍAZ CABIALE, 2015)

\section{INVERSÃO DO ÔNUS DA PROVA À LUZ DOS PRINCÍPIOS CONSTITUCIONAIS}

Tema que merece muita atenção está na possibilidade de inversão do ônus da prova para a comprovação dos ganhos/produtos indevidos. Para tanto, tal prerrogativa processual precisa ser manejada sem que implique violação ao princípio da presunção de inocência. Assim, são necessários critérios para a delimitação da atuação da acusação e do órgão julgador, a serem adotadas pelos estados-membros no âmbito de seu direito interno.

Voltando-se ao Código Penal Espanhol, foram estabelecidas uma série de presunçôes iuris tantum que buscam dar solidez suficiente à origem criminosa dos bens (desproporção dos bens, transferências opacas, propriedade fictícia, paraísos fiscais, etc.).

O problema, já apontado pela doutrina, é se essas disposições normativas não estão no limite da configuração do confisco geral de bens $^{30}$. De fato, o confisco pode ser estendido a todos os bens do condenado e, pelo menos na hipótese regulamentada no artigo 127 bis da lei penal espanhola, não seria necessário vincular esses bens à atividade criminosa do sujeito, tampouco há a necessidade de comprovar a participação efetiva do proprietário do imóvel em um ato criminoso específico.

29 DÍAZ CABIALE, José Antonio. El Decomiso tras las reformas del Código Penal y la Ley de Enjuiciamiento Criminal de 2015. Revista Electrónica de Ciencia Penal y Criminología., n. 18, 2016, ISSN 1695-019, ISSN-e 1695-0194, p. 1-70, p. 3/4.

30 Sobre o tema, BOTTINI, Pierpaolo Cruz. Direito penal, processo penal e colaboração premiada na lei “anticrime”. Consultor Jurídico. 6. jan. 2020, Disponível em: https://www.conjur.com.br/2020jan-06/direito-defesa-direito-penal-processo-penal-delacao-lei-anticrime. Acesso em: 09 ago. 2021. 
Nessa senda, o Tribunal Constitucional Espanhol se manifestou favoravelmente à tese da prova indiciária, quando da alteração promovida pela Ley Orgánica 5/2010 ao artigo 127 do CP Espanhol, de que modo que o juiz ou tribunal deveriam ampliar o decomiso aos bens, instrumentos e proventos derivados de atividades criminosas, cometidas no âmbito de uma organização ou grupo criminoso ou terrorista, na ocasião na qual valor auferido fosse desproporcional à renda legalmente obtida por cada um dos condenados, e, deste modo, haveria a presunção de que tais valores seriam derivados da atividade criminosa,

Sobre o tema, Aguado Correa (2014, p. 30),verbis:

En cuanto a la validez de la prueba indiciaria para acreditar el origen delictivo de los bienes decomisados, recordemos que el Tribunal Constitucional se ha pronunciado en los siguientes términos:

"Sentado lo anterior, en el presente caso, tanto la Sentencia de instancia como la de casación explican suficientemente las razones por las que se considera acreditado que los bienes decomisados eran propiedad del recurrente y se adquirieron con el producto obtenido de la venta de estupefacientes, lo que justifica el comiso de los mismos, conforme a lo previsto tanto en el art. 127 del Código penal (CP) como específicamente en el art. $374 \mathrm{CP}$ y ello a través de una clara prueba indiciaria" (STC 219/2006, FJ 9; 220/2006, FJ 8). La prueba indiciaria también ha sido utilizada desde hace muchos años por el Tribunal Supremo en el ámbito de los delitos de blanqueo de capitales, tanto para la infracción penal 12 como para el decomiso. Respecto de este último, en la Sentencia de 5 de diciembre de 2012, el TS ha afirmado:

"En relación a la primera circunstancia, es decir del origen ilícito, hay que tener en cuenta que esta procedencia ilícita puede quedar acreditada mediante prueba indirecta o indiciaria, y que la demostración del origen criminal -presupuesto imprescindible para decretar el comiso - no requiere la identificación de las concretas operaciones delictivas, bastando a tales efectos que quede suficientemente probada la actividad delictiva de modo genérico. Así lo ha entendido esta Sala en el delito de blanqueo respecto del delito antecedente o determinante (SSTS 10.11.2000, 28.7.2001, 5.2.2003, 10.2.2003, 14.4.2003, 29.11.2003, 19.1.2005 y 20.9.2005). 
Em continuação ao expressado anteriormente, novamente Aguado Correa (2014, p. 31$)^{31}$ elucida:

De ahí la importancia de recordar la garantía contemplada en el apartado 4 del art. 8 PD, referida a la presunción de probabilidad en relación con el decomiso ampliado: "En el procedimiento contemplado en el artículo 4, el sospechoso o acusado tendrá la posibilidad efectiva de impugnar la presunción de probabilidad en la que se basa la consideración de que los bienes en cuestión constituyen productos del delito".

$Y$ es que si bien las presunciones legales no impiden el ejercicio del derecho a defensa, la existencia de éstas otorga ciertas ventajas a la acusación y consecuentemente genera desventajas para la defensa, ya que el acusador no tiene que esforzarse en probar un extremo relativamente complejo como es la vinculación entre el delito y los bienes que se pueden considerar producto de aquél, sino que le basta con probar el indicio que exige la ley ${ }^{114}$.

En el ejercicio del derecho de defensa, como ha subrayado GASCÓN INCHAUSTI, se puede probar el origen lícito de los bienes, debiéndose aplicar las consecuencias del principio in dubio pro reo, de forma tal que si el tribunal tiene dudas razonables tras la justificación de los bienes facilitada por el acusado, no debe decretar el comiso; por otra parte, el acusado debe poder impugnar el enlace entre el indicio legal y el hecho presunto en que basa la presunción, es decir, debe tener la oportunidad de demostrar la inoperancia de la máxima de la experiencia. ${ }^{115}$

A Exposição de Motivos da Lei Orgânica de Espanha 1/2015, que promoveu as demais modificações na lei penal para adequações das figuras do perdimento de bens, veio a sustentar que o decomiso ampliado não se tratava de uma penalidade, mas sim de uma medida de natureza civil, próxima à situação de enriquecimento ilícito/injusto, que visa dar resposta a uma situação patrimonial ilícita. Leia-se:

31 Citações contidas no texto: 114 - GASCÓN INCHAUSTI, El decomiso transfronterizo, p. 95. No obstante, en opinión de este autor, esta desventaja para la defensa se vería contrarrestada por el elevado grado de seguridad jurídica que aporta una presunción legal frente a una presunción judicial, ya que el acusado conoce previamente cuales son los indicios y los enlaces que se pueden utilizar en su contra. 115 - GASCÓN INCHAUSTI, El decomiso transfronterizo, p. 96. Trae a colación este autor lo dispuesto en el apartado 2 del art. 385 LEC, precepto dedicado a las presunciones legales. 
El decomiso ampliado no es una sanción penal, sino que se trata de una institución por medio de la cual se pone fin a la situación patrimonial ilícita a que ha dado lugar la actividad delictiva. Su fundamento tiene, por ello, una naturaleza más bien civil y patrimonial, próxima a la de figuras como el enriquecimiento injusto. El hecho de que la normativa de la Unión Europea se refiera expresamente a la posibilidad de que los tribunales puedan decidir el decomiso ampliado sobre la base de indicios, especialmente la desproporción entre los ingresos lícitos del sujeto y el patrimonio disponible, e, incluso, a través de procedimientos de naturaleza no penal, confirma la anterior interpretación ${ }^{32}$.

Em resumo, a desvinculação do processo de perdimento de bens do processo penal, em si, passa a permitir que a decretação do decomiso ocorra em um feito autônomo, desvinculada da pretensão punitiva do agente, com lastro na inversão do ônus da prova da (i)licitude dos bens do réu e dos demais integrantes de organizações criminosas, podendo o confisco incidir sobre todo o lastro patrimonial que se apresente desproporcional para com os ingressos obtidos de forma comprovadamente lícita pelos autores do delito.

Para o direito brasileiro, a inserção de medidas semelhantes a nossa legislação, especialmente as que versam sobre a inversão do ônus probatório, devem ser analisadas à luz do princípio constitucional da presunção de inocência, pelo qual se garante que ninguém será considerado culpado até o trânsito em julgado de sentença penal condenatória (art. $5^{\circ}$, inciso LVII, CF/88), em que pese a Lei n. 9.613, de 1998, já prever, em relação aos crimes de lavagem de dinheiro, a inversão do ônus da prova sobre a licitude da origem de bens apreendidos no curso desses processos $\left(\operatorname{art} .4^{\circ}, \S 2^{\circ}\right)^{33}$ :

32 Boletín Oficial del Estado. Leu Orgánica 1/2015. Disponível em: https://www.boe.es/buscar/doc. php?id=BOE-A-2015-3439. Acesso em: 03 jun. 2021.

33 Art. 4o O juiz, de ofício, a requerimento do Ministério Público ou mediante representação do delegado de polícia, ouvido o Ministério Público em 24 (vinte e quatro) horas, havendo indícios suficientes de infração penal, poderá decretar medidas assecuratórias de bens, direitos ou valores do investigado ou acusado, ou existentes em nome de interpostas pessoas, que sejam instrumento, produto ou proveito dos crimes previstos nesta Lei ou das infrações penais antecedentes. (Redação dada pela Lei $\mathrm{n}^{\circ} 12.683$, de 2012)

$\$ 4$ o Poderão ser decretadas medidas assecuratórias sobre bens, direitos ou valores para reparação do dano decorrente da infração penal antecedente ou da prevista nesta Lei ou para pagamento de prestação pecuniária, multa e custas. (Redação dada pela Lei nº 12.683, de 2012). 
A privação dos bens que compõem o patrimônio do acusado, como ato de confisco desarrazoado, em certos casos, pode ser mais gravosa que a condenação à pena de restrição de liberdade. De qualquer modo, para garantir um resultado final útil da persecução penal, necessário seria que as atuais disposições sobre a apreensão e sequestro de bens, previstas na Lei de Lavagem de Dinheiro pátria, nos limites constitucionais, fossem ampliadas para todos os demais delitos, evitando-se manobras tendentes à dilapidação do patrimônio por parte do acusado que temesse por futura condenação.

Em outra senda, para realmente ser evitado o enriquecimento ilícito, a boa-fé de terceiros deve ser interpretada de forma restritiva. Assim, a valoração da lisura do adquirente deve estar em consonância como o seu incremento patrimonial ordinário ${ }^{34}$.

Hipótese mais evidente se revela quando a maior parte dos bens adquiridos pelo acusado está em nome de membros de sua família, que, de regra, não têm renda própria. Nesse caso, seguindo-se o aqui esposado, a inversão do ônus da prova seria medida imperativa para a recuperação dos ativos provenientes da lavagem de dinheiro para a devida repressão do crime e para o combate à corrupção ${ }^{35}$.

34 Consejo General Del Poder Judicial. Procedimiento de Recurso de Apelación contra Sentencia n. 6/2020. (28079220642020100006) En el acto de la vista al ratificarse en su demanda el ministerio fiscal se refirió al decomiso de todos los bienes inmuebles, muebles, sociedades y cuentas bancarias, que se relacionan en los hechos, y de manera complementaria que si alguno ha desaparecido del tráfico jurídico que se estime la demanda por valor equivalente en la cantidad de 900.000 euros. En los hechos de la demanda se mencionan además ingresos y gastos en que incurren los hijos, dinero que pasó por sus cuentas bancarias, sin que sobre estas cuentas conste su saldo (excepto en relación a la cuenta de Tamara ), compras de vehículos que se van sustituyendo, parece que todo ello podría servir de base a un decomiso por sustitución, al que aludió el ministerio fiscal en la vista, pero para que esta acción pudiese prosperar sería necesario que precisasen las cuantías del decomiso por sustitución que solicita en relación con cada demandado. No lo hace así en la demanda, aunque es una exigencia del art. 803 ter de la L.E.Crim. y ello impide su consideración.

Aunque la demanda se dirige contra los cinco hijos de Ismael no se puede estimar contra Tomasa, porque no aparece como titular de los bienes cuyo decomiso se acuerda. Este decomiso no resulta desproporcionado a la actividad delictiva desarrollada por Ismael, porque las ganancias procedentes de la actividad delictiva aparecen como único origen de los bienes. La proporcionalidad sería aplicable para atemperar el decomiso cuando se tratase de bienes adquiridos en parte con ganancias ilícitas y en parte lícitas, lo que no es el caso. Disponível em: https://www.poderjudicial.es/search/documento/ AN/9260080/estructura\%20del\%20delito/20200924. Acesso em: 02 jun. 2021.

35 Para maior detalhamento do tema, ARAS, Vladimir. Sistema nacional de combate à lavagem de dinheiro e de recuperação de ativos. Revista Jus Navigandi, Teresina, ano 12, n. 1411, maio 2007. Disponível em: https://jus.com.br/artigos/9862/sistema-nacional-de-combate-alavagem-de-dinheiro-e-de-recuperacao-de-ativos. Acesso em: 09 ago. 2021. 
O encadeamento lógico urge ser a essência do debate no caso concreto - "ou seja, a defesa deve ser exercida levando-se em conta os fatos e as circunstâncias que deram origem à prova indiciária" ${ }^{\text {"36 }}$

Outrossim, no que diz respeito à relação entre Brasil e Espanha temos, como exemplo, o Acordo de Cooperação Mútua, celebrado em 2006, que previu a colaboração entre os países, mesmo que a conduta investigada não seja considerada delito pelo ordenamento jurídico da parte requerida ${ }^{37}$.

\section{Projetos de lei para modificação do código DE PROCESSO PENAL BRASILEIRO}

Apenas para contextualizar o presente artigo com os desdobramentos legislativos em curso no Brasil, urge salientar a existência do Projeto de Lei Complementar n. 156/2009 e o Projeto de Lei n. $8045 / 2010$, os quais abordam a necessidade de harmonização dos preceitos do código de processo penal brasileiro com os princípios democráticos da constituição de 1988.

No que toca ao perdimento de bens, fora feita proposição para incluir a indisponibilidade dos bens do acusado, lícitos ou ilícitos, como medida cautelar. Assim, pelos projetos (hoje apensados), são medidas cautelares reais i) indisponibilidade de bens; ii) sequestro de bens; iii) hipoteca legal; iv) e arresto de bens.

O projeto ainda permite que bens abandonados ou cujo proprietário não tenha sido identificado sejam postos em indisponibilidade ou sequestrados pela Justiça.

A inovação de maior alcance está em permitir a alienação cautelar dos bens sequestrados, sem o aguardo do o trânsito em julgado

36 LINHARES, Cícero Sólon. O branqueamento de capitais, a prova indiciária e os princípios da legalidade e ampla defesa. Revista de Direito Econômico e Socioambiental, Curitiba, ISSN 2179-345X, v. 1, n. 1, p. 75.

37 BRASIL. Decreto n. 6.681, de 8 de dezembro de 2008. Promulga o Acordo de Cooperação e Auxílio Jurídico Mútuo em Matéria Penal entre a República Federativa do Brasil e o Reino da Espanha, celebrado em Brasília, em 22 de maio de 2006. Diário Oficial da União, Poder Executivo, Brasília, DF, 9 dez. 2008. Disponível em: http://www.planalto.gov.br/ccivil_03/_ ato2007-2010/2008/decreto/d6681.htm. Acesso em: 02 jun. 2021. 
da sentença condenatória como condição prévia, em havendo receio de depreciação patrimonial ou perecimento pelo decurso de tempo, ante os custos de conservação.

\section{Conclus Ão}

De fato, o mundo passou por uma série de crises, sejam financeiras, ecológicas e agora sanitárias. Como ensina Santos (2020), estamos vivendo em um estado de crise constante. Infelizmente, essa sequência de crises veio a justificar, em alguns países, a adoção de diversas medidas que permitiram, inclusive, movimentos impensáveis em regimes democráticos atuais, como, por exemplo, a redução dos direitos trabalhistas ou a precariedade do sistema de saúde ou educação. ${ }^{38}$

Impedir que a atuação estatal esteja dissociada do real fim do Estado é o primeiro passo para alcançar a verdade politica ${ }^{39} \mathrm{e}$ a proteção dos direitos inerentes aos indivíduos.

Para as hipóteses em apreço caberá ao Poder Judiciário, nos casos concretos, definir o perfeito equilíbrio entre as partes processuais ${ }^{40}$.

38 SOUZA Santos, Boaventura. Uma cruel pedagogia do vírus. Almedina. Lisboa, 2020. p 5. Disponível em: http://www.abennacional.org.br/site/wp-ontent/uploads/2020/04/Livro_ Boaventura.pdf. Acesso em: 19 nov. 2020.

39 Vid. ARENDT, Hannah. Verdade e Política. Lisboa: Lisboa Editora. 2005. Tradução comentários de Luís Lourenço.

40 Mais detidamente sobre o tema, AGUADO CORREA, Teresa. Decomiso de los productos de la delincuencia organizada: garantizar que el delito no resulte provechoso. Revista Electrónica de Ciencia Penal y Criminología. 2013, núm. 15-05, p. 05:1-05:27 - ISSN 1695-0194, p. 3. "A la hora de tomar decisiones sobre medidas de Derecho Penal destinadas a garantizar la aplicación efectiva de las políticas de la Unión Europea que son objeto de medidas de armonización, el legislador de la UE deberá seguir, en opinión de la Comisión9, dos pasos: en un primer paso, decidir si debe adoptar medidas o no de Derecho Penal, teniendo presente los postulados del principio de necesidad y proporcionalidad, siendo el Derecho Penal el instrumento de último recurso ("ultima ratio")10; en un segundo paso, una vez que se demuestre la necesidad de recurrir al Derecho Penal, se deben tener en cuenta una serie de principios rectores de la decisión sobre qué tipo de medidas de Derecho penal adoptar, debiéndose tener presente además unas normas mínimas, la necesidad y proporcionalidad y la adecuación de las sanciones a los delitos 11, entre otras, requiriendo el estudio de cuestiones como la necesidad de acordar medidas adicionales como la incautación, de la cual nos ocupamos en este trabajo12." Citações contidas no texto: 9 - COM (2011) 573 final, págs. 10 y ss. 10 - Sobre la importancia del principio de proporcionalidad en Derecho Penal, vid. AGUADO CORREA, El principio de proporcionalidad en Derecho Penal, Madrid, 1999, passim. En nuestro trabajo sobre El comiso, Madrid, 2000, pág. 73, pusimos de manifiesto la necesidad de tener muy presente el principio de subsidiariedad en la lucha contra la criminalidad organizada, en particular, en la regulación de las sanciones debiéndose tener muy presente el grado de efectividad de las sanciones patrimoniales y formas de intervención alternativas. 11 - TIEDEMANN, en "Exigencias fundamentales de la Parte 
E ao fazê-lo, deve levar em conta o princípio da proporcionalidade em sua dupla perspectiva, quais sejam, a da proibição do excesso e a da proibição de proteção deficiente ou insuficiente, de modo a não impor restrições inadequadas, desnecessárias ou desproporcionais aos direitos fundamentais do acusado, sem deixar, por outro lado, de promover a proteção eficiente e completa dos demais direitos fundamentais previstos na Constituição da República.

Em arremate, sobre o tema da proporcionalidade, Aguado Correa (1999, p. 144-145), verbis:

Sobre la diferente terminología que se utiliza, razonabilidad-racionalidad, es importante decir que en tanto que la razonalidad es el parámetro que se utiliza normalmente en Estados Unidos; en Europa, por el contrario, es la razonabilidad. Sin embargo, y a pesar de las diferencias terminológicas, ambos test son exactamente iguales al basarse ambos en la «aplicación pura y simple de la teoría de los valores respecto a determinados preceptos, como puntualiza el mismo autor, la razonabilidad o racionalidad se convierten en el parámetro por excelencia del examen de constitucionalidad de actos o normas.

E ainda prossegue, aclarando que "la medida de constitucionalidad en que consiste el test de razonabilidad en sentido amplio, constituye un método de interpretación por el cual se han desarrollado múltiples preceptos constitucionales" ${ }^{\prime \prime}$.

$\mathrm{Na}$ Espanha, o princípio da proporcionalidade, o qual responde à ideia de evitar o uso excessivo de sanções que impliquem privação ou restrição de liberdade, encontra sua justificativa em diferentes preceitos da Constituição Espanhola, embora não o incluído expressamente no texto constitucional.

O primeiro artigo já proclama o Estado de Direito e o maior bem, a liberdade, assim como o artigo 10.1, o qual referenda a dignidade da pessoa e o livre desenvolvimento da personalidade.

General y propuesta legislativa para un Derecho Penal europeo", Revista Penal, n. 3, pág. 77, destacó la importancia de la noción constitucional de proporcionalidad en Europa, recordando que el Proyecto de Corpus Juris para la creación de un espacio penal europeo común en torno a la protección de los intereses financieros de la Comunidad, subrayaba expresamente que el principio de legalidad, culpabilidad y proporcionalidad de las penas y medidas de seguridad son principios básicos del Derecho penal europeo. 12- COM (2011) 573 final, pág. 13.

41 idem, ibidem. 
No Brasil, o princípio da proporcionalidade também está implícito no texto constitucional, no entanto, no plano infraconstitucional, foi homenageado pelo art. $2^{\circ 42}$ da Lei n. 9.784, de 1999, a qual regulamenta o processo administrativo no âmbito da Administração Pública Federal.

É inegável que o direito penal moderno se apresenta de tal forma que sua intervenção nas relações sociais deveria ser mínima, já que a criminalização demasiada não é meio útil para a resolução de problemas sociais, sendo ilusória a transformação do direito penal em um instrumento pedagógico, simplesmente por estar voltado à criminalização incessante, com a criação de tipos penais vagos e de perigo abstrato.

Em um país como o Brasil, com clássicos problemas advindos da estratificação social, a problemática apresentada é ainda mais grave, pois o trinômio necessidade-utilidade-efetividade, na maior parte das vezes, não é observado.

Assim, o papel da justiça restaurativa ${ }^{43}$ é orientar as partes envolvidas na demanda para buscar a resolução dos conflitos pelo diálogo, de modo a tornar este mister mais humano e mais equilibrado, sem perder sua efetividade, uma vez que a reprimenda aos delitos é de extrema importância para a sociedade.

Em um país onde a desigualdade social é característica chave de sua identidade, infelizmente, os açoites corporais ainda recairão sobre os menos favorecidos.

De todo modo, o ius puniendi precisa ser exercido para resguardar o bem penal tutelado, independentemente da classe social da qual pertença o infrator. Não se olvida que a imposição de restrições corporais, em muitos casos, não auxilia o sistema penal, apenas o sobrecarrega e faz com que paire na sociedade um sentir de impunidade. E é sob esta perspectiva que o instituto do decomiso urge ser valorado.

42 Art. 2o A Administração Pública obedecerá, dentre outros, aos princípios da legalidade, finalidade, motivação, razoabilidade, proporcionalidade, moralidade, ampla defesa, contraditório, segurança jurídica, interesse público e eficiência.

43 Conselho Nacional de Justiça. Disponível em: https://www.cnj.jus.br/programas-e-acoes/ justica-restaurativa/. Acesso em: 03 jun. 2021. 
Respeitados os preceitos constitucionais da garantia do contraditório, da ampla defesa e da individualidade da pena, pode-se ter relevante mecanismo de defesa para a sociedade que é refém de organizações criminosas, as quais, por vezes, conseguem se apropriar do próprio Estado. Assim, confia-se em haver compatibilidade entre as premissas aqui lançadas e a Constituição Federal de 1988 do Brasil, de modo que a legislação pátria pode ser ainda mais aprimorada (em que pese os inúmeros projetos de leis em tramitação em nossas Casas Legislativas), para o combate efetivo ao crime organizado, permitindo a privação de bens, de lucros e, quiçá, de direitos advindos da atividade criminosa de forma efetiva, tanto quanto ao tempo, quanto à forma de implementação destas medidas.

\section{Flávia do Espirito Santo Batista}

Advogada da União na Consultoria Jurídica Adjunta junto ao Comando da Aeronáutica

MÁster UNIVERSITÁRIo EN DERECHO PUBLICO / Universidad de Sevilla

Especialista en DEREChos Funtamentales PEla Universidade Castilla la Mancha, Toledo - Espanha,

(2010).

Pós-graduação lato sensu em Processo Civil pela PUC/SP (2009).

GraduaÇão em CiênCias Jurídicas e Sociais pela Universidade Federal do Rio de Janeiro (2001).

http://lattes.cnpq.br/7303369393281643

\section{Mauricio Macagnan da Silva}

Advogado da UNIão NA

Procuradoria-Regional da União da 1. Região

MÁster UNIVERSITÁRIo EN DERECHO PÚBLICO /

Universidad de Sevilla.

GRAduaÇão em Engenharia Mecânica pela Universidade Federal do Rio Grande do Sul(1994)

E EM CiÊnCIAS JuRídicas E Sociais PEla Universidade Federal do Rio Grande do Sul(2002)

http://lattes.cnpq.br/2749966466953778 


\title{
DECOMISO IN SPANISH LAW. A POSSIBILITY FOR BRAZIL, GIVEN THE INNOVATIONS OF LAW N. 13,964, OF 2019?
}

\begin{abstract}
The present article sought to analyze the political-criminal feasibility, under the aspect of the legitimacy of the Decomiso, the content of the latest reforms promoted by the Organic Law of Spain 1/2015, of March 30, to Brazilian law.

KEYwORDS: confiscation; illicit assets ; criminal organizations ; constitutional guarantees.

\section{DECOMISO EN DERECHO ESPAÑOL. ¿UNA POSIBILIDAD PARA BRASIL, DADAS LAS INNOVACIONES DE LA LEY N ${ }^{\circ} 13.964$, DE 2019?}

\section{RESUMEN}

El presente trabajo buscó analizar la viabilidad político-penal, bajo el aspecto de la legitimidad del instituto Decomiso, a la luz de las últimas reformas impulsadas por la Ley Orgánica de España 1/2015, de 30 de marzo, a la legislación brasileña.

Palabras-Clave: decomiso ; propiedad ilícita; organizaciones criminales ; garantías constitucionales. 


\section{REFERÊNCIAS}

AGUADO CORREA, Teresa. El Principio de Proporcionalidade em Derecho Penal. Ed. Edersa: Madrid, 1999.

- Comiso: crónica de una reforma anunciada: análisis de la propuesta de directiva sobre embargo y decomiso de 2012 y del proyecto de reforma del Código Penal de 2013. Indret: Revista para el Análisis del Derecho, La Rioja, n. 1, p. 1-56, jan., 2014. ISSN 1698739X. 2.21.

. Decomiso de los productos de la delincuencia organizada: garantizar que el delito no resulte provechoso. Revista Electrónica de Ciencia Penal y Criminología, 2013, n. 15-05, p. 5:1-05:27 - ISSN 1695-0194.

ARAS, Vladimir. Sistema nacional de combate à lavagem de dinheiro e de recuperação de ativos. Revista Jus Navigandi, Teresina, v. 12, n. 1411, maio 2007. Disponível em: https://jus.com.br/artigos/9862/ sistema-nacional-de-combate-a-lavagem-de-dinheiro-e-derecuperacao-de-ativos. Acesso em: 09 ago. 2021.

ARENDT, Hannah. Verdade e Politica. Lisboa: Lisboa Editora, 2005. Tradução e comentários de Luís Lourenço.

BECCARIA, César. Tratado sobre infrações e penalidades. Ministério da Justiça da Espanha, 1993, p. 216.

BOBBIO, Norberto. Teoria geral da política: filosofia política e as lições dos clássicos. Rio de Janeiro: Campus, 2000.

BOTTINI, Pierpaolo Cruz. Direito penal, processo penal e colaboração premiada na lei "anticrime". Consultor Jurídico. 6. jan. 2020, Disponível em: https://www.conjur.com.br/2020-jan-06/ direito-defesa-direito-penal-processo-penal-delacao-lei-anticrime. Acesso em: 9 ago. 2021.

BRASIL. Código Penal Brasileiro. Decreto-Lei n. 2.848, de 7 de dezembro de 1940.

BRASIL. Lei n. 9.714, de 25 de novembro de 1998. Altera dispositivos do Decreto-Lei no 2.848, de 7 de dezembro de 1940 Código Penal. 
BRASIL. Lei n. 13.964, de 24 de dezembro de 2019. Aperfeiçoa a legislação penal e processual penal.

DÍAZ CABIALE, José Antonio. El Decomiso tras las reformas del Código Penal y la Ley de Enjuiciamiento Criminal de 2015. Revista Electrónica de Ciencia Penal y Criminología, n. 18, _p. 1-70, 2016. ISSN 1695-019, ISSN-e 1695-0194.

ESPANHA. Código Penal Espanhol. Lei Orgânica 10/1995, de 23 de novembro de 1995.

FERRAJOLI, Luigi. Direito e razão: teoria do garantismo penal. 2. ed.. Tradução de Ana Paula Zomer Sica, Fauzi Hassan Choukr, Juarez Tavares e Luiz Flávio Gomes. São Paulo: Editora Revista dos Tribunais, 2006, p. 785-786.

FOUCAULT, Michel. Vigiar e punir: nascimento da prisão.

Tradução de Raquel Ramalhete. Petrópolis: Vozes, 1987.

KELSEN, Hans. Teoria pura do direito. Tradução de: João Baptista Machado. 8. ed. São Paulo: WMF Martins Fontes, 1999.

LINHARES, Cícero Sólon. O branqueamento de capitais, a prova indiciária e os princípios da legalidade e ampla defesa. Revista de Direito Econômico e Socioambiental, Curitiba, ISSN 2179-345X, v. 1, n. 1, p. 65-80, jan./jun. 2010.

MENDONÇA, Thaiane. Eleições e milícias no Rio de Janeiro: simbiose entre o poder público e o crime organizado. Disponível em: https://gedes-unesp.org/eleicoes-e-milicias-no-rio-de-janeirosimbiose-entre-o-poder-publico-e-o-crime-organizado/. Acesso em: 31 maio 2021.

MONTESQUIEU, Charles de Secondat, Barão de. O espirito das leis, El Cid Editor, 2016.

RODRIGUEZ, Garcia Nícolas. Encuentros multidisciplinares, v.22, n. 65, 2020. (Artigos publicados previamente na Revista internacional de transparencia e integridad, 2016-2019).

SANTOS, Boaventura de Souza . Uma cruel pedagogia do vírus. Almedina: Lisboa, 2020

VIEIRA, Dias Adriana. Significado de Penas e Tratamentos Desumanos Análise Histórico-Jurisprudencial Comparativa 
Decomiso no direito espanhol. Uma possibilidade para o brasil, ante as inovaçôes...

em Três Sistemas Jurídicos: Brasil, Europa e Estados Unidos. Rivista L'altro diritto - Centro di ricerca interuniversitario su carcere, devianza, marginalità e governo delle migrazioni, Pacini Giuridica Editore, 2007. 